\title{
The Importance of Inclusive Spaces in Social Skills Development: Drawing on the LGBTQ Educational and Disability Studies in Education Frameworks
}

\author{
Aja McKee,a, Audri Sandoval Gomez ${ }^{b}$, Kevin Stockbridge ${ }^{c}$
}

Received
Revised
Accepted

17 June 2020

9 October 2020

28 December 2020

$\mathrm{DOI}$

10.26822/iejee.2021.198

a: Correspondance Details: Aja McKee,

California State University, California, USA.

E-mail: amckee@fullerton.edu

ORCID: https://orcid.org/0000-0002-8675-895X

${ }^{b}$ Audri Sandoval Gomez,

Thompson Policy Institute on Disability, Chapman

University, California, USA

E-mail:agomez@chapman.edu

ORCID: https://orcid.org/0000-0002-5671-4198

'Kevin Stockbridge,

Chapman University, California, USA.

E-mail: kstock@chapman.edu

ORCID: https://orcid.org/0000-0002-3859-943X

\begin{abstract}
This manuscript highlights a major finding from a larger study conducted in the United States that used phenomenological interviews with adults with autism who typed to communicate. Participants shared their United States educational experiences before and after learning to type. This finding focused on how disability studies in education and the development of inclusive spaces, such as those designed for lesbian, gay, bisexual, transexual, and queer or questioning (LGBTQ) students, may change the way in which educators support students with autism in developing and sustaining natural and meaningful friendships. Thus, this paper examined the social experiences of one participant who had an inclusive education from preschool through college graduation, and whose experience with participation in a social club, described as an acceptance coalition for the LGBTQ community, can influence the way in which educators provide support for building relationships with peers beginning in the elementary school setting.
\end{abstract}

\section{Keywords:}

Autism, Social Skills, Evidence-Based Practices, LGBTQ

\section{Introduction}

Examining the history of special education intervention Ein the United States including evidence-based practices (EBPs) for students with autism, sheds insight into how special educators currently support students with autism in developing skills. These skills include the development of social skills, which special educators hope result in relationships with peers. EBPs, developed in the United States, provide flexibility for professionals when deciding what may or may not work for individuals with autism; however, they may also limit educators in how to best support the students they serve. EBPs are not meant to be implemented in lieu of professional advice, but to complement it and support positive results (Cook et al., 2008). The challenge may be that providing a determined set of practices may limit special educators from thinking outside the box. Special educators may feel compelled to choose an EBP when trying to teach students with autism to interact and develop 


\section{iejee $\approx$}

social relationships. Additionally, using EBPs in autism to provide social interventions developed for a disability defined by a set of behaviors can be problematic. It is critical we examine how EBPs are derived and the implications in supporting the needs of all students.

\section{Special Education Intervention and EBPs}

The literature on autism oscillates between education and psychology where "most modern interventions for autism are educational in nature," while "most research on interventions has either been carried out by psychologists, published in psychological journals, or both" (Mesibov \& Shea, 2011, p. 115). The history of the research on interventions can be seen in the development of EBPs. EBPs in special education derive from EBPs in United States psychology, which evolved out of the field of medicine (Mesibov \& Shea, 2011; West et al., 2013). In an effort to continue to support adult psychotherapy in the 1990s, the American Psychological Association (APA) attempted to position itself within managed-care and insurance plans (Mesibov \& Shea, 2011). One way to do this was by developing EBPs and reinforcing the discipline of psychology with an empirically based foundation (Mesibov \& Shea, 2011). EBPs in special education integrate literature and expert experience, as opposed to research-based practices, which may only rely on research literature (West et al., 2013). EBPs are defined as "a strategy or intervention designed for use by special educators and intended to support the education of individuals with exceptional learning needs" (Council for Exceptional Children, 2008, p. 6).

\section{Challenges with EBPs in Autism}

There are challenges associated with EBPs in autism. Two of these challenges that have been substantiated in this research include a) a limited consensus on most effective intervention, and b) how autism is defined and the perception of the behaviors associated with the disability. Mesibov and Shea (2011) suggested that there are financial implications for using or not using EBPs. Using EBPs leads the public to believe the intervention to be sound and allows the people and organizations that use these practices to demand public funds for their implementation. What this means is it is desirable for practitioners to prove their evidence-based status and disprove that of their competitors, who may be competing for public acknowledgment and funding. Further, an examination of various organizations that have aimed to identify evidence-based interventions for autism (Bodfish, 2004; Interactive Autism Network Community, 2010; National Autism Center, 2016) use different definitions of EBPs and numerous interventions. Subsequently, the reviews resulted in minimal consensus about the most effective evidence-based intervention for individuals with autism (Mesibov \& Shea, 2011) since various treatments worked for some individuals, but not for others.

\section{Another Barrier: Autism Defined}

To add to this challenge, a changing definition of autism has led to a specific view of the disability. In the most recent edition of the Diagnostic and Statistical Manual of Mental Disorders 5 (APA, 2013), the mention of motor movement is listed under restrictive, repetitive patterns of behavior and is defined as stereotyped or repetitive motor movements. Further, deficits of social communication, social interaction, and a continued focus on behavior, drive the definition of autism (APA, 2013). Autism is often viewed through a behaviorist lens, which is problematic for educators. The problem is that a behaviorist perspective looks at body movement strictly as behavior, with that behavior being "good" or "bad." For example, when discussing Parkinson's disorder, there is often an impairment of voluntary movements known as akinesia (Mena et al., 2008), meaning individuals with the disorder are unable to make their body move as they wish. While this behavior is viewed as involuntary when displayed by an individual with Parkinson's, the social interpretation of this behavior for people with autism is a lack of compliance or social indifference (Donnellan et al., 2010). According to Donnellan et al. (2010), the social interpretation of this movement in a behavioral context for people with autism would be that the individual is lazy or slow. This is problematic when educators misinterpret slow or inability to control movement in students with autism, because the struggle becomes about compliance. One way to begin to shift educators' thinking when it comes to autism and behavior is through a disability studies in education (DSE) framework.

\section{DSE and Autism Intervention}

DSE is described as the social model of disability. DSE tenets include (a) contextualize disability within political and social spheres; (b) privilege the interests, agendas, and voices of people labeled with disability/ disabled people; (c) promote social justice, equitable and inclusive educational opportunities, and full and meaningful access to all aspects of society for people labeled with disability/disabled people; and (d) assume competence and reject deficit models of disability (Connor et al., 2008, p. 448).

A DSE framework allows educators to examine disability through a socially just lens focused on "recognizing and removing the barriers and creating equitable access" (Cosier \& Ashby, 2016, p. 5). Too often educators target the deficits or differences of an individual to guide instruction or one's schooling. In turn, ableism influences how students with disabilities (SWD) are viewed in education, exacerbating the notion of inferiority to their nondisabled peers (Ashby, 2012; Linton, 1998). Examining the social skills of SWD, special educators tend to focus on what students are unable to do compared to their nondisabled peers, which 
ultimately abstains their peers and themselves from acceptance of SWD for who they are. Through DSE, educators can readjust their approaches to instruction and intervention to focus on accommodations and acceptance. Ultimately, according to Corbett (1999), "there may be a commitment to social justice and equality of opportunity in a comprehensive school, but in direct conflict with this, may be deep-rooted assumptions (beliefs and fears) about intelligence, ability and social class, which inevitably influence teachers' behaviour in the classroom and in their daily interactions in school" (p. 55). A DSE framework focuses less on the prescriptiveness of implementing EBPs and the deficits of an individual. The following research finding illustrates an alternative approach to the use of EBPs that focuses on individual voice.

\section{Jacob's Story of Success}

In a recent phenomenological study that examined the United States educational experiences of individuals with autism who typed to communicate (McKee \& Sandoval Gomez, 2020), one finding highlighted an alternative to using EBPs to teach social skills. In the larger study, purposeful sampling was used to find participants who had autism, were non-speaking or had minimally reliable speech, and used typing as their main form of communication. Participants in this study had varying levels of communication needs that were addressed through a support person. The support person provided one or multiple of these accommodations such as physical touch at the elbow, shoulder, or above, verbal encouragement, prompting to stay focused, or feedback on unclear typed messages. Jacob typed without physical accommodations from his support person and read his typed words aloud.

During his interview, Jacob shared that he participated in a social club in school. This club was designed with LGBTQ inclusion as a central tenet. LGBTQ social spaces, like Jacob's club, operate from a number of core principles which frame their practice. LGBTQ frameworks are less standardized than the DSE construct, preventing an authoritative enumeration of its tenets. Nonetheless, we do note that these two frameworks often overlap on core ideals. Both the DSE and LGBTQ frames, center the voices and experiences of individuals who are traditionally marginalized and approach social justice as a process of inclusion. LGBTQ organizations, much like the club in which Jacob participated, frame the issues LGBTQ persons experience as effects of an alienating social construction of identity. They seek to correct this through alternative constructions of social life that are more inclusive and affirming.

Students who identify as LGBTQ encounter a number of significant challenges in their school experiences.
Seen as nonnormative due to their sexual orientation and/or gender identity, many of these youth face verbal bullying, a lack of a sense of safety, and violence (Kosciw et al., 2018). The most significant response to this reality has been the development of student organizations whose focus is developing safe and inclusive spaces for these students (Fetner \& Kush, 2008). These organizations are often called GSAs (i.e., gay-straight alliances or gender and sexuality alliances). Research has shown the presence of these organizations correlates with reports of more positive school climates and fewer discriminatory experiences for LGBTQ youth (Davis et al., 2014; Kosciw et al., 2018).

Jacob's club valued acceptance and provided its participants with the opportunity to connect with peers and have fun around food and conversation. This club provided a space for students to get together to cook, eat, chat, and hang out. Although Jacob was the only student to communicate through typing, he found the experience to be an important and life-changing one when it came to building peer relationships. Jacob described the experience of eating lunch with friends: "The possibility of lunch dates. It's challenging when one is a typer and the other not, but these life connections formulate an opportunity for growth. You are emotionally taking a risk more than really is comfortable at times." When asked about the impact of the club, Jacob replied, "So very connecting with vital friends." He also stated, "Fun and pleasing the soul of bold journey." When the researcher explained this was different from her experience, which centered on forming groups that focused on intervention, where students with autism were taught to learn specific social skills that targeted overcoming deficits identified by the definition of the disability, Jacob posited, "Simply devastating the heart."

This important finding needed to be explored further for two reasons. First, groups of people such as individuals who are considered "disabled" have traditionally been marginalized and undervalued for their contribution to society and research. Asking Jacob what helped him be successful socially, as an individual with autism, and why he believes this practice was successful, is key. Oftentimes professionals believe their knowledge base is all they need to determine what interventions will work for the individuals they serve and do not ask the individuals themselves. This is problematic in special education because this practice further empowers the professional and devalues the thoughts of the student with the disability.

The second reason is that targeting the skill of developing social relationships in a natural environment within a space of acceptance, as opposed to a place of intervention with the expectation of overcoming one's disability and striving for normalization, 


\section{iejee}

deserves to be further explored. In Jacob's situation, if educators would have used EBPs when working with him to develop social skills, his deficits would have been the focus with the intervention being contrived adult-led experiences. Jacob would have not had the opportunity to engage in authentic friendships. Educators need to establish an environment where all individuals are accepted, have a sense of belonging, and are a part of the community (Pearpoint \& Forest, 1992), which align with a DSE and LGTBQ framework.

\section{Discussion}

Students with autism of all ages need and deserve opportunities to initiate and build friendships in spaces where they are not sent the message of needing to overcome their disability. Special education is designed to bridge the gap of skills, promote educational access, and deliver what educators hope are outcomes students would want for themselves as they age. Oftentimes, able-bodied educators make decisions about what students with disabilities should learn, pushing an able-bodied agenda upon others (Kitchin, 2000). This may occur more often in elementary school when, due to age, children may struggle to identify what is important to them. However, even young children, such as those in elementary school, should be listened to and their interests and strengths should be the primary focus as educators strive to develop safe and inclusive environments that send messages of acceptance.

Most GSAs are intentionally created as spaces of inclusion, open to people of any gender or sexual identity (Fetner \& Kush, 2008). Rather than taking a medical/treatment approach to nonnormativity, these clubs, led by youth of diverse identities, constitute communities predicated on the acceptance of difference as valuable. Having a space in which LGBTQ students experience positive and affirming social interactions empowers them to face personal and institutional obstacles (Lee, 2002). GSAs engage in activities that serve to affirm and strengthen a collective sense of belonging, educate the school community, and effect positive change in school policies (Poteat et al., 2017).

Both the DSE and LGBTQ frameworks argue for a model of inclusion. Educators should consider support for students that is most holistic, less medical model, and more authentic rather than have students remain in the silos created by traditional social stratification (e.g. ability, sexuality, age, and gender). Educators need to confront previously existing beliefs that we know best and be willing to think outside the box and entertain new ideas. Part of thinking outside the box includes examining what other marginalized groups of students have encountered.

\section{Conclusion}

Jacob's story of navigating social opportunities, specifically with the social club, demonstrates how he obtained authentic social experiences in a space focused more on acceptance. This space allowed for genuine opportunities where Jacob thrived and built meaningful relationships. The rigidness of EBPs can sometimes hinder the purity of natural social opportunities. In Jacob's situation, imposing practices such as EBPs inadequately supported the development of his social needs and identity. Jacob's story reminds educators to be open to listen to our students, allow for authentic social opportunities to happen, and provide the space for these occurrences. Carrington (1999) reminded us when the values and beliefs of an experience, and more importantly a school experience, match the nondiscriminatory language in the foundations of inclusion, the culture will impact the classroom in a way where all students feel welcomed, are involved, and are full members of the community.

\section{References}

American Psychiatric Association. (2013). Diagnostic and statistical manual of mental disorders (5th ed.). Author.

Ashby, C. (2012). Disability studies and inclusive teacher preparation: A socially just path for teacher education. Research and Practice for Persons with Severe Disabilities, 37(2), 89-99.

Bodfish, J. W. (2004). Treating the core features of autism: Are we there yet? Mental Retardation and Developmental Disabilities Research Reviews, 10(4), 318-326. https://www.doi. org/10.1002/mrdd.20045

Carrington, S. (1999). Inclusion needs a different school culture. International Journal of Inclusive Education, 3(3), 257-268. https://doi. org/10.1080/136031199285039

Connor, D. J., Gabel, S. L., Gallagher, D. J., \& Morton, M. (2008) Disability studies and inclusive education-Implications for theory, research, and practice. International Journal of Inclusive Education, 12(5-6), 441-457. https://doi. org/10.1080/13603110802377482

Cook, B. G., Tankersley, M., \& Harjusola-Webb, S. (2008). Evidence-based practice and professional wisdom: Putting it all together. Intervention in School and Clinic, 44(2), 105-111. https://doi. org/10.1177/1053451208321566

Corbett, J. (1999). Inclusiveeducation and school culture. International Journal of Inclusive Education, 3(1), 53-61. https://doi.org/10.1080/136031199285183 
Cosier, M., \& Ashby, C. (2016). Disability studies and the "work" of educators. In M. Cosier \& C. Ashby (Eds), Enacting change from within: Disability studies meets teaching and teacher education (pp. 61-81). Peter Lang Publishing.

Council for Exceptional Children. (2008). Classifying the state of evidence for special education professional practices: CEC practice study manual.

Davis, B., Stafford, M., \& Pullig, C. (2014). How gaystraight alliance groups mitigate the relationship between gay-bias victimization and adolescent suicide attempts. Journal of the American Academy of Child and Adolescent Psychiatry, 53(12), 1271-1278. https://www. jaacap.org/article/S0890-8567(14)00662-5/pdf

Donnellan, A., Hill, D., \& Leary, M. (2010). Rethinking autism: Implications of sensory and movement differences. Disability Studies Quarterly, 30(6), 1-11. https://doi.org/10.3389/fnint.2012.00124

Fetner, T., \& Kush, K. (2008). Gay-straight alliances in high schools: Social predictors of early adoption. Youth \& Society, 40(1), 114-130. https:// doi.org/10.1177/0044118X07308073

Interactive Autism Network Community. (2010, June 15). Autism treatment: What do we really know? http://www.iancommunity.org/cs/what_do_ we_know/overview

Kitchin, R. M. (2000). The researched opinions on research: Disabled people and disability research. Disability \& Society, 15(1), 25-47. https:// doi.org/10.1080/09687590025757

Kosciw, J., Greytak, E., Zongrone, A., Clark, C., \& Truong, N. (2018). The 2017 national school climate survey: The experiences of lesbian, gay, bisexual, transgender, and queer youth in our national schools. GLSEN.

Lee, C. (2002). The impact of belonging to a high school gay/straight alliance. The High School Journal, 85(3), 13-26. https://doi.org/10.1353/ hsj.2002.0005

Linton, S. (1998). Claiming disability: Knowledge and identity. New York University Press.

Mckee, A., \& Sandoval Gomez, A. (2020). The voices of typers: Examining the educational experiences of individuals who use facilitated communication. Disability Studies Quarterly, 40(4). http://dx.doi.org/10.18061/dsq.v40i4.6981
Mena, M. A., Rodriguez-Navarro, J. A., Ros, R., \& De Yebenes, J. G. (2008). On the pathogenesis and neuroprotective treatment of Parkinson disease: What have we learned from the genetic forms of this disease? Current Medicinal Chemistry, 15(23), 2305-2320. https://doi. org/10.2174/092986708785909148

Mesibov, G. B., \& Shea, V., (2011). Evidence-based practices and autism. Autism, 15(1), 114-133. https://doi.org/10.1177/1362361309348070

National Autism Center. (2016). National Autism Center's National Standards Project (2006-2016). May Institute. http://www.nationalautismcenter. org/about/development.php

Pearpoint, J., \& Forest, M. (1992). Forward. In S. Stainback \&W. Stainback (Eds.), Curriculum considerations in inclusive classrooms: Facilitating learning for all students (pp. xv-xviii). Paul H. Brookes.

Poteat, V., Yoshikawa, H., Calzo, J, Russel, S., \& Horn, S. (2017). Gay-straight alliances as settings for youth inclusion and development: Future conceptual and methodological directions for research on these and other student groups in schools. Educational Researcher, 46(9), 508-516. https://doi.org/10.3102/0013189X17738760

West, E. E., McCollow, M., Kidwell, J., Umbarger, G., \& Cote, D. L. (2013). Current status of evidencebased practice for students with intellectual disability and autism spectrum disorders. Education \& Training in Autism \& Developmental Disabilities, 48(4), 443-455. https://www.jstor. org/stable/24232502 